\title{
Early childhood wheezers: identifying asthma in later life
}

Anayansi Lasso-Pirot

Silvia Delgado-Villalta

Adam J Spanier

Department of Pediatrics, University of Maryland School of Medicine, Baltimore, MD, USA
Correspondence: Adam J Spanier University of Maryland Midtown Campus, 300 Armory Place, Suite 2B2042,

Baltimore, MD 2I 20I, USA

$\mathrm{Tel}+\mathrm{I} 4108563828$

Fax + I 4I08563897

Email aspanier@peds.umaryland.edu
This article was published in the following Dove Press journal:

Journal of Asthma and Allergy

13 July 2015

Number of times this article has been viewed

\begin{abstract}
Wheeze in young children is common, and asthma is the most common noncommunicable disease in children. Prevalence studies of recurrent asthma-like symptoms in children under the age of 5 years have reported that one third of children in the US and Europe are affected, and rates and severity appear to be higher in developing countries. Over the last few decades, significant research efforts have focused on identification of risk factors and predictors of wheeze and on tools to identify which children who wheeze will progress to develop asthma. We reviewed the phenotypes of childhood wheezing, genetic risk factors, environmental factors, testing/predictive indices, and primary prevention. While it is generally agreed that a complex interaction of environmental exposure and genetic susceptibility contributes to the development of asthma, limitations in predictive tools and tests restrict our ability to provide families with guidance as to whether their child with wheeze will ultimately develop asthma. Additional research is needed to clarify childhood wheeze phenotypes, to develop tools to determine which children will develop asthma, and to determine how and when to intervene. If these areas can be addressed, it would help reduce this large burden on children, families, and society.
\end{abstract}

Keywords: asthma, child, wheeze

\section{Introduction}

The presence of wheezing suggests obstruction in the lower airways. ${ }^{1}$ The most frequent causes of wheezing in early childhood are bronchiolitis and asthma. ${ }^{1}$ While bronchiolitis is usually self-limited, it can sometimes recur. Recognizing which children have transient recurrent wheezing due to bronchiolitis or other causes, and which children will have disease that evolves into chronic asthma is an issue that caregivers and medical providers would like to be able to address. This information is essential to determine how children with recurrent wheezing are treated and to determine what to expect in the future.

Recurrent wheeze in early life is a significant cause of respiratory morbidity. ${ }^{2}$ Prevalence studies of children under 5 years of age with symptoms suggestive of asthma have reported that one third of children in the USA and Europe are affected, and rates and severity appear to be higher in developing countries. ${ }^{2}$ Asthma is the most frequent non-infectious disease in children. ${ }^{3}$ Approximately 235 million people worldwide are asthmatics, with an increasing prevalence in low to middle income countries. ${ }^{3}$ However, in the developing world, and to a lesser degree in the first world, wheezing and asthma in preschool children can be falsely diagnosed as pneumonia and undertreated, because definitions of these disorders overlap. ${ }^{1}$ Recurrent wheeze in young 
children, either transient or due to asthma, can be severe and cause significant impairment in quality of life, with frequent use of health care systems and great expense. ${ }^{1,2}$

Risk of recurrent wheeze, as well as established asthma, may be increased among those of lower socioeconomic status. In one study of 30,093 children aged 12-15 months, the mean prevalence of recurrent wheezing in Latin America was $21.4 \%$ and in Europe was $15.0 \%$, suggesting a possible association with income. ${ }^{2}$ Another study of 23,065 US children reported that individual-level poverty was an independent predictor of asthma prevalence. ${ }^{4}$

Wheezing is a symptom that is multifactorial, and in young children usually relates to bronchiolitis or an early presentation of asthma. Other less common conditions also associated with wheezing are congenital anatomical abnormalities, foreign body aspiration, other pulmonary disorders (eg, cystic fibrosis), and cardiac, immune, and gastrointestinal disorders, which need to be considered in cases with atypical presentation. ${ }^{1}$ Despite the high prevalence of early childhood wheeze, $60 \%$ of young wheezers improve and are symptom-free by the age of 6 years, and a majority of these children remain asymptomatic at the ages of 11 and 16 years. ${ }^{5}$ Determination of which children will continue to wheeze is important for providers who direct treatment, families who want to know what to expect, and public health planning.

What factors and exposures present during early life determine whether wheezing will be transient or lifelong asthma? Evidence derived from the Tucson's Children Respiratory Study suggests that Th-2-like responses, characteristic of atopic asthma, are established very early in life. ${ }^{5}$ While these responses are established early, determination of transient early wheezing from an early presentation of asthma has important implications and is a challenging question to address (Figure 1).

Considerable investigation has been directed at the longterm prognosis of early childhood wheeze, risk factors for early wheeze developing into asthma, and tools to predict which children will develop asthma. ${ }^{6}$ However, despite the vast work in the area, the factors that influence the development of asthma following childhood recurrent wheeze remain complex and not well understood. In this review, we focus on seminal publications on the topic of early childhood wheeze and on recent publications to summarize the current evidence for the multiple factors that have been linked to childhood wheeze and persistence of childhood wheezing and the methods that may help predict which children with wheeze may develop chronic asthma.

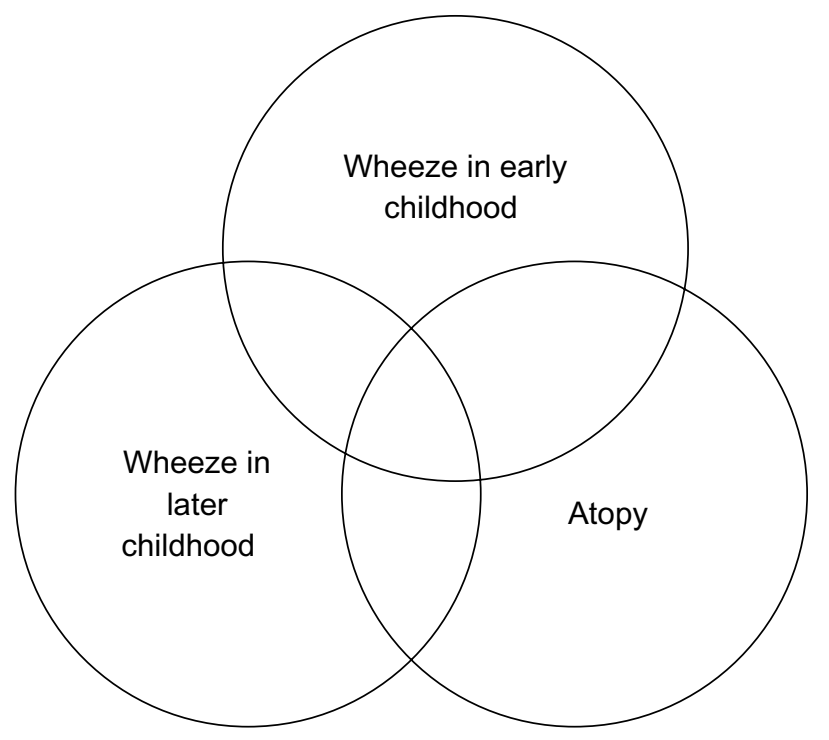

Figure I Venn diagram demonstrating the complex interplay of wheeze, age, and allergy. Note: True asthma is in the intersection of the wheeze circles, and atopic asthma is at the intersection of the three.

\section{Summary of the evidence Phenotypes/variability}

As noted previously, wheezing episodes are common in young infants, and clinicians are frequently faced with the uncertainty of knowing if infants with recurrent wheezing will develop asthma. The application of unbiased statistical approaches has led to the definition of several phenotypes of asthma and represents a major advance in the last few years. ${ }^{7}$ Currently, the most frequently used clinical asthma classification system is the one adapted from the 2007 National Heart, Lung, and Blood Institute Guidelines for the Diagnosis and Treatment of Asthma Expert Panel Report 3. The system classifies asthma according to the frequency of symptoms, impairment, and risk. However, most clinicians recognize limitations in the current classification system because it attempts to provide a single system to address the different asthma phenotypes and asthma subtypes. These guidelines recognize that treatment cannot be the same for all asthma phenotypes but should be based on the pathophysiology of each group.

Aiming to identify unique phenotypes of pediatric asthma, some studies have concentrated on clustering of childhood asthma phenotypes. Fitzpatrick et al described four pediatric asthma clusters or phenotypes distinct from the adult clusters: cluster 1, ie, late onset (mean age, 73 months) symptomatic asthma with normal lung function (late-onset/ normal lung); cluster 2, ie, early onset (mean age, 30 months) atopic asthma with normal lung function (early-onset/normal lung); cluster 3, ie, earliest onset (mean age, 14 months) atopic asthma with mild airflow limitation and greater 
comorbidity (early-onset/comorbidity); and cluster 4, ie, early onset (mean age, 17 months) atopic asthma, advanced airflow limitation, and greatest medication use (early-onset/ severe lung). ${ }^{8}$ Another study, performed by Chang et al, was also able to replicate these four pediatric clusters. ${ }^{7}$ Both studies were able to identify pediatric asthma clusters that were different to those found in adults, but were not able to provide different treatment recommendations.

In another prospective study of children with a family history of asthma, investigators showed a significant relationship between an elevated level of total immunoglobulin (Ig) $E$ at the age of 6 months and a future diagnosis of asthma at the ages of 6 and 8 years. ${ }^{9}$

One of the most widely cited classification systems for childhood wheeze comes from the prospective Tucson Children's Respiratory Study. ${ }^{10,11}$ Childhood wheeze patterns were grouped into categories of never wheeze, transient wheeze, persistent wheeze, and late onset wheeze, depending on the presence or absence of wheeze before the age of 3 years and through to age 6 years. Atopy was also part of the classification of wheeze. Differentiation of children with transient wheeze from those with persistent and late-onset wheeze is of key clinical importance, but currently remains mostly an aspiration.

The Dutch birth cohort in Prevention and Incidence of Asthma and Mite Allergy (PIAMA) and the birth cohort in Avon Longitudinal Study of Parents and Children (ALSPAC) also identified phenotypes of child wheezing, some of which persisted into later childhood and a diagnosis of asthma. PIAMA presented five categories of child wheeze, including never/infrequent, transient early, intermediate-onset, lateonset, and persistent. The intermediate-onset, late-onset, and persistent categories were most strongly associated with doctor-diagnosed asthma at the age of 8 years. ${ }^{12}$ These categories were similar in ALSPAC and identified an additional phenotype beyond the Tucson Children's Respiratory Study, ie, the intermediate-onset phenotype. ${ }^{12}$ Additional work is needed to identify the unique phenotypes of childhood wheeze and which ones predict the development of asthma.

\section{Genetic factors}

As the previous section noted, asthma consists of many complex phenotypes, so identifying a singular genetic cause of asthma is unlikely. ${ }^{13}$ Moreover, identifying a single environmental cause is equally unlikely. Multiple studies have suggested that asthma is multifactorial and occurs by the interaction of genetic and environmental factors that lead to the typical features of asthma.
Genetic studies of asthma have revealed that there is some heritability to the phenotypes, and there has been some limitation to genetic studies because of the lack of standardized asthma phenotypes. Despite this limitation, a large number of candidate gene studies have identified many genes associated with immune function that are potentially involved in the pathogenesis of asthma. ${ }^{13}$ Nevertheless, many studies have failed to be replicated, leaving in question the true impact of the implicated biological pathways. ${ }^{7}$

Yang et al reported on a birth cohort study designed to investigate the genetic and environmental risk factors for early childhood wheezing. ${ }^{14}$ Throughout the observation period, a significant percentage of the infants $(22 \%)$ had at least one wheezing episode and $6.6 \%$ had recurrent wheezing, with more than three episodes in a period of 18 months. ${ }^{14}$ Cord blood immunoglobulin E level, male sex, second-hand cigarette smoke exposure, and parental history of atopy were reported as predictive risk factors for recurrent wheezing. The investigators concluded that recurrent wheezing was associated with the Clara cell protein $C C 10 \mathrm{G}+38 \mathrm{~A}$ polymorphism and lower CC10 levels, but was not associated with infant atopy. ${ }^{14}$

Investigators have evaluated other genetic markers in the inflammatory pathways in a search for markers that can help to identify the risk of developing persistent asthma. Several single nucleotide polymorphisms in the IL33-IL1RL1 pathway have been evaluated in birth cohorts, and have been associated with intermediate-onset wheeze, late-onset wheeze, and persistent wheeze. ${ }^{15}$

Another study, performed in Egyptian children, evaluated a single nucleotide polymorphism in tumor necrosis factor alpha (TNF- $\alpha$ ), a major proinflammatory cytokine. The investigators reported a higher frequency of TNF- $\alpha$ $308 \mathrm{G} / \mathrm{A}$ in asthmatic children $(60 \%)$ and wheezy infants $(68 \%)$ when compared with the control group (30\%). This study suggested that a variation in TNF- $\alpha 308$ is a potential genetic factor contributing to the development of wheezing and childhood asthma. ${ }^{16}$

Multiple genome-wide association studies have also demonstrated difficulties in replicating findings across the phenotypes of childhood asthma. One genome wide association study found a new locus in chromosome 17q12-q21, that involves the genes $O R M D L 3, G S D M B$, and $Z P B 2$, associated with asthma. ${ }^{17}$ The most commonly reported variant is in the $17 \mathrm{q} 21$ locus, representing the GSDMB and ORMDL3 genes. ${ }^{18-20}$

Multiple genome wide association studies have been performed in other populations. A genome wide association 
study performed in Australia found a significant association in the gene that codes for the interleukin (IL)- 6 receptor and in chromosome 11q13.5. ${ }^{21}$ Another genome wide association study looked for genetic variants in Latino populations, and reported a significant association in locus 6P21, which they report as replicable in other analyses involving Latino populations. They also found the previously identified association on locus $17 q 21 .^{22}$ Despite replication of a few genetic loci, these prominent variants account for only a relatively small proportion of asthma heritability. ${ }^{23}$

Identifying genes associated with early wheezing and asthma may help to provide early diagnosis and treatment of asthma in the future. At the same time, it opens the possibility for specific pharmacotherapy to address the dysregulation responsible for the symptoms. As in the case of the IL-6 receptor, tocilizumab, a medication antagonizing the IL-6 receptor, could be a potential treatment for this particular asthma genotype. ${ }^{21}$

\section{Environmental factors and exposures}

Environmental factors are thought to have a role in causing asthma exacerbations and may have a role in the development of asthma. Climate change, for example, may be playing a role in the timing and load of exposure to aeroallergens. It is also possible that factors that cause asthma exacerbations are linked to the development of lifelong asthma.

Extensive evidence has accumulated over several decades to support that air pollution and other factors can exacerbate lung disease, but a relationship with the development of asthma is not well established. ${ }^{24,25}$ The hygiene hypothesis proposes a mechanism by which fewer infections in early life and lower exposure to microbes may modify the immune system, shifting towards a Th2-biased allergic response in early life. ${ }^{26}$ Altered exposures to microbial flora (causing changes in the intestinal microbiome) have also been suggested to be associated with the increasing prevalence of asthma and other allergic conditions. ${ }^{27}$ This concept is supported by observations that the risk of asthma is reduced among children living on farms, suggesting that greater exposure to microbial contaminants in early childhood may be protective against asthma. ${ }^{26}$

Exposures to tobacco smoke, crowding, pets, and pests, among others, have been linked to asthma. Mice, mold, dust mites, pets, cockroaches, and cigarette smoke are all considered important indoor allergens and irritants, and as such have been linked to asthma exacerbations. ${ }^{27}$ The level and interactions between these exposures, and relationships with other factors, such as the genetic background of the individual and age at exposure, may explain, at least in part, the increase in the worldwide incidence of wheezing conditions and, possibly, the development of lifelong asthma.

\section{Air pollution}

Short-term exposure to air pollution is well documented to cause exacerbations of asthma, decreased lung function, and increased admissions for respiratory symptoms. ${ }^{28,29}$ Air pollution is increasing with population growth. Traffic-related pollution is an increasing problem and may be a major contributor to asthma flares. ${ }^{29,30}$ In the USA, approximately $4 \%$ of the population lives within close distance of a major highway, causing increased exposure to traffic-related pollution with an elevated risk for adverse respiratory outcomes. ${ }^{30}$

In a recent study reporting episodes of asthma symptoms and use of after hours health services during two periods of poor air quality in England in early 2014, there was a statistically significant rise in a range of acute respiratory conditions (difficulty breathing, wheeze, asthma). ${ }^{31}$ During those periods, local emissions, combined with atmospheric transport of dust from the Sahara and emissions from continental Europe, in conjunction with anticyclonic weather conditions, led to several days with high to very high levels of particulate air pollution across most of the UK. ${ }^{31}$

Another environmental exposure, ie, wild fire smoke, is increasing. ${ }^{32}$ Exposure to wild fire smoke has been linked to flares of asthma. ${ }^{29,32}$ In a recent review of 61 studies on the impact of exposure to wild fire smoke, the majority found that wild fire smoke was linked to an elevated risk of respiratory conditions. ${ }^{32}$ Children, the elderly, and those with underlying chronic diseases appeared to be more susceptible to these exposures. ${ }^{32}$ In fact, the risk of respiratory-related hospital visits associated with wild fire smoke was higher for children younger than 5 years compared with other age groups. ${ }^{32}$

Many cities in the developing world are undergoing rapid population growth accompanied by increased outdoor air pollution, and there is broad consensus that climate change is increasing environmental exposures and the threat of forest fires. With these increases, the global burden of new-onset asthma and asthma symptoms is likely to increase. ${ }^{33}$

\section{Tobacco exposure}

Tobacco smoke is a significant indoor air pollutant and can interact with other air pollutants to elicit poor respiratory outcomes during childhood. ${ }^{24}$ There is evidence that smoking during pregnancy increases the risk of childhood asthma. Intrauterine exposure can occur either by the mother's smoking, or by the mother's exposure to tobacco smoke 
during pregnancy. Tobacco byproducts are then transferred across the placenta to the fetus. ${ }^{24}$

A cohort study of 499 children of atopic parents in Boston reported that maternal smoking during pregnancy was linked to an increased risk of asthma symptoms in the first year of life. ${ }^{34}$ In a Finnish birth cohort of almost 60,000 children, the risk of having asthma at age 7 years increased in a dosedependent manner among mothers with higher smoking rates during pregnancy (odds ratio 1.25, 95\% confidence interval $1.09-1.44$ for $<10$ cigarettes/day and odds ratio $1.36,95 \%$ confidence interval $1.14-1.63$ for $>10$ cigarettes/day). ${ }^{35}$

There are also animal data to suggest that epigenetic changes due to prenatal smoke exposure might be inherited by second-generation offspring, with potential consequences for an asthma-related phenotype. ${ }^{36}$ Human data are limited, but a recent mother and child cohort study in Norway reported that the grandmother's smoking when pregnant with the mother increased the risk of asthma in the grandchild, independent of the mother's smoking status. ${ }^{36}$

\section{Exposure to pets/pests/indoor mold}

Results from studies of pet sensitization, atopy, and asthma are complex, and suggest different effects that depend on age at exposure, degree of exposure, and sensitization status. The most common cat and dog allergens are Fel $\mathrm{d} 1$ and Can $\mathrm{f} 1$, and are found in skin, hair follicles, and saliva. ${ }^{27}$ Some studies report that pet exposure may be protective against atopy and the development of asthma, while others suggest the opposite. ${ }^{37-40}$

Mouse allergen is common in homes and schools in inner cities. Concentrations in these homes are high, and children living in inner city homes are frequently sensitized. ${ }^{27}$ However, a study in Baltimore showed significant indoor mouse allergen exposure in suburban homes as well, and exposure was linked to sensitization. ${ }^{41}$

Children in the northeastern USA with greater levels of mouse allergen exposure in inner city schools have been found to have more asthma-related missed school days. ${ }^{27}$ Exposure to mouse allergen has been also linked to the presence of wheeze in the first 12 months of life and later. ${ }^{27,42,43}$

Cockroach exposure is considered to be a significant factor related to the high prevalence of asthma in inner city children. ${ }^{44}$ Exposure to cockroach allergens was reported to correlate with the development and severity of asthma in sensitized children. ${ }^{44}$ The same study, interestingly, did not find this association with exposure to cats and dust mite in the children studied. It was postulated that the level of these allergens in the houses sampled was low, making the assessment less accurate. ${ }^{44}$
Dust mite exposure is more frequent in crowded and humid indoor environments, and average humidity levels $>50 \%$ have been shown to be more likely to have elevated dust mite allergen levels. ${ }^{45}$ The main allergens related to the house dust mite species Dermatophagoides farinae and Dermatophagoides pteronyssinus are found in mite feces. It appears that there is a dose-response relationship between dust mite exposure and sensitization. ${ }^{27}$ Dust mite allergen sensitization in asthmatics is related to increased symptoms with more health care utilization, including increased rescue medication use, unscheduled outpatient visits, and hospitalizations for respiratory flares. ${ }^{46}$ The risk of having a diagnosis of asthma has also been shown to increase in young children with early exposure to high levels of dust mite allergen $(\geq 10 \mu \mathrm{g} / \mathrm{g}){ }^{47}$

Mold exposure in the home is frequently linked to exacerbations of asthma. The Pollution and the Young study obtained data on exposure and health parameters in 57,161 children aged 6-12 years in 12 countries. ${ }^{48}$ Indoor mold exposure was clearly associated with respiratory symptoms (wheeze, nocturnal cough, sensitivity to inhaled allergens, and allergic rhinitis) in children across different countries. However, these results were based on self-reported questionnaires, limiting their accuracy. Improved methods to detect fungi in the indoor environment are available; however, they are not widely used, and additional work is needed to study the role of fungi exposure on children's health. ${ }^{48}$ It is likely that fungi exposure causes health problems in humid environments, but the evidence has not been clearly established. ${ }^{48}$

The concentration of bacterial endotoxins (lipopolysaccharides found in the outer membranes of Gram-negative bacteria) in house dust correlates with the presence of pets in the house, in particular that of dogs. ${ }^{27}$ Some authors, however, have found no correlation between the presence of cats and dogs in the home and the level of endotoxins, and found increased levels in cold weather, with cockroaches in the home, with crowding, with frequent use of floor cloths, and with infrequent vacuuming. ${ }^{27}$ Indoor endotoxins seem to increase the risk for respiratory symptoms in early childhood and may be related to the severity of these symptoms in children with allergic asthma. ${ }^{49,50}$

\section{Crowding}

People in industrialized countries spend nearly $90 \%$ of their time indoors, and two thirds of this time is spent at home. Infants may spend 20 hours per day in their homes. ${ }^{51}$ This indoor time increases exposure to indoor contaminants as well as exposure to other people. Crowding may increase the 
levels of exposure to indoor pollutants, so may be associated with an increased risk of developing asthma and increased severity of asthma. ${ }^{51}$

\section{Daycare attendance}

Studies examining the effect of daycare attendance on the development of asthma have demonstrated inconsistent results. A recent publication on the presence of an asthma diagnosis at age 7 years in 589 children in Cincinnati reported that having attended daycare can increase or decrease the risk of having asthma, depending on the duration of attendance during the first 12 months of life. ${ }^{52}$ Specifically, cumulative hours of daycare at 12 months was associated with 1.2 times the odds of asthma; however, more than 37.5 hours per week of daycare attendance was associated with lower odds of asthma (odds ratio $0.6,95 \%$ confidence interval $0.4-0.9$ ). ${ }^{52}$ In general, however, studies on this topic have frequently been based on parental recollection of the presence of respiratory infections during attendance at daycare in early life, so are subject to recall and reporting biases.

\section{Respiratory infections}

Viral infections during infancy are common and frequently present prior to the development of asthma. Despite significant research efforts to identify the role of specific viral infections in the development of asthma, it remains unclear if specific viral infections during early childhood can lead to having asthma later in life.

In a prospective study of 259 children from birth to 6 years of age, investigators attempted to identify a relationship between early childhood asthma development and viral infections. ${ }^{53}$ A viral pathogen was found in $90 \%$ of patients presenting with a wheezing episode. The study reported an increased risk of developing asthma at age 6 years in those patients who had wheezing triggered by respiratory syncytial virus infection, rhinovirus infection, or both. Rhinovirus infection-related wheezing during the first year of life was associated with an increased risk of asthma at age 6 years. Nearly $90 \%$ of the children who had wheezing episodes with rhinovirus infection at 3 years of age had clinical asthma at the age of 6 years. The results from this study lead to the conclusion that infant wheezing with rhinovirus infection is a significant predictor for later development of clinical asthma. $^{53}$

Another study evaluated 630 infants who presented with upper respiratory tract infection or bronchiolitis. This study showed that human rhinovirus infection frequently triggered bronchiolitis and upper respiratory illnesses in previously healthy infants and frequently was the cause of hospitalization or sick outpatient visits. The study described a higher severity in illness in children whose mothers had a history of atopy. ${ }^{54}$

In a community-based cohort study of 198 children at risk of atopy, followed from birth to the age 5 of years, aspirates for viral identification were collected during respiratory illnesses. Rhinovirus infection (48.3\%) was the predominant virus observed, followed by respiratory syncytial virus $(10.9 \%)$. At the end of the study, $28.3 \%$ of the children had current wheeze, and there was an association between lower respiratory infection, particularly rhinovirus infection, and persistent wheeze. The association was present in those children with early sensitization and not in those without a history of atopy. The results of this study led to the conclusion that development of asthma is multifactorial and that viral infections early in life likely play a role in the development of asthma. ${ }^{55}$

Evidence has shown that double-stranded RNA from respiratory viruses cause significant airway hyperresponsiveness and pulmonary inflammation in a mouse model. ${ }^{56}$ There is evidence showing increased secretion of a Th2 cytokine from the respiratory epithelium in response to respiratory virus infection, ie, thymic stromal lymphopoetin. ${ }^{57}$

Another pathogen that has been related to the pathophysiology of asthma is Chlamydia pneumonia. In a study by Zaitsu et al, infection with Chlamydia pneumonia was identified by looking at the serum of infants presenting with wheezing. The children were followed for 1 year to determine if asthma could be associated with this type of infection. The investigators reported that infants with Chlamydia pneumonia and wheezing progressed to asthma more frequently than those who were not infected, and concluded that Chlamydia infection during infancy can be involved in the later development of asthma. ${ }^{58}$

\section{Breastfeeding}

Breastfeeding is almost universally recommended and has been proposed as a way to prevent atopic disease. However, a recent large study, ie, the Promotion of Breastfeeding Intervention Trial, found no reduction in risk of asthma or other atopic diseases at the age of 6 and a half years in breastfed children. ${ }^{59}$ The results of other publications are mixed, however, and another recent study examining the association between breastfeeding and the risk of having asthma symptoms at age 3 and a half years in children whose mothers self-identified as Latinas in Los Angeles, reported a $49 \%$ reduction in risk for children breastfed exclusively for 
the first 12 weeks of their lives. ${ }^{60}$ The results of the effects of breastfeeding on the risk of developing asthma and allergies in children are equivocal, partly due to many of the studies being observational only. However, it is clear that lack of breastfeeding is associated with a 15 -fold increased risk of pneumonia in children. ${ }^{3}$ It is possible that reductions in childhood infectious respiratory diseases through infant breastfeeding will impact the long-term incidence of childhood asthma.

\section{Early exposure to allergenic foods}

Another topic of importance in the development of childhood atopic diseases, including asthma, is dietary exposures in early life. ${ }^{61}$ One study that analyzed data from 2,073 children reported that if the introduction of solid food is delayed beyond 4-6 months, it did not decrease atopy at the age of 6 years, and did not decrease the prevalence of asthma or sensitization against foods in that age group. ${ }^{62,63}$ Findings related to eczema were equivocal, and eczema appeared to be more frequent in those children with a more diverse diet during the first 4 months of life. ${ }^{62,63}$

Data for the same cohort focused on children with parental allergy, and demonstrated no protective effect of delayed food exposure on atopic outcomes. The only outcome that demonstrated some protection from delayed exposure was food allergen sensitization. Food allergen sensitization was 3.2 times more frequent ( $95 \%$ confidence interval 1.5-6.9) when food was introduced at 4-6 months and 2.5 times more frequent when food introduction was delayed beyond 6 months (95\% confidence interval 1.03-6.30). ${ }^{62,63}$ This was one of the longest prospective cohorts at the time, following children to 6 years of age, and because of the design was less susceptible to recall bias. ${ }^{63}$ The reported results are in line with an American Academy of Pediatrics clinical report published in 2008, which also concluded that delayed introduction of foods beyond 4-6 months did not protect against atopic diseases, including the introduction of very allergenic foods, such as fish, eggs, and peanuts. ${ }^{64}$

\section{Testing/biomarkers/predictive screens}

One of the existing limitations in studying and diagnosing asthma in young children is that the pathological hallmarks of asthma, ie, airflow limitation and chronic airway inflammation, are difficult to measure objectively in young children. Many studies have tried to find a tool to predict asthma in early childhood wheezers, but this goal remains elusive. ${ }^{65}$

In a study by Castro Rodriguez el al, an attempt was made to create a tool, ie, the asthma predictive index, to help in identifying the likelihood of later development of asthma in children with wheezing early in childhood. The factors included in the strict version of the index require at least three episodes of wheezing per year during the first 3 years of age, and one major criteria (doctor-diagnosed eczema or parental asthma) or two minor criteria (doctor-diagnosed allergic rhinitis, wheezing without colds, or $\geq 4 \%$ peripheral blood eosinophils). If a child has a positive index, they have a $77 \%$ likelihood of asthma at 6-8 years of age and a 50\% likelihood of asthma at 11-13 years of age. If a child has a negative index, they only have a $10 \%$ likelihood of asthma at 6-8 years and a $15 \%$ likelihood of asthma at $11-13$ years. ${ }^{66}$ Despite its limitations, many physicians currently use the asthma predictive index as a tool for early prediction of asthma in young children and to provide more information for parents about the likelihood of their child having asthma in the future.

Investigators have also explored airway inflammatory markers as measured in exhaled breath condensates. Measurement of airway inflammatory markers in preschoolers with a history of persistent wheezing showed elevated airway inflammation markers, ie, IL-2, IL-4, IL-8, IL-10, and soluble intercellular adhesion molecules when compared with children without wheezing. ${ }^{67}$ However, measurement of exhaled breath condensate is difficult and time-consuming among young children.

The fraction of exhaled nitric oxide (FeNO) has been proposed as a marker of eosinophilic-predominant inflammation in the airways. Several studies have reported higher levels of FeNO in preschoolers with recurrent wheezing and atopy when compared with other preschoolers who have wheezing without atopy. ${ }^{68-72}$ However, FeNO is not an easy test to perform in young children, and is likely to be more beneficial for use in subsets of asthma.

A prospective study compared the predictive values of single-breath FeNO, tidal breathing mixed FeNO, clinical response to bronchodilators, and the asthma predictive index devised by Castro Rodriguez et al in infants and toddlers with a history of recurrent wheezing over 3 years. The study results demonstrated that more than 30 parts per billion in a single-breath FeNO could predict persistence of wheezing at age 3 years with a sensitivity of $77 \%$ and a specificity of 94\%. The single-breath FeNO measure had better sensitivity, specificity, and positive and negative predictive values for the prediction of a later diagnosis of asthma when compared with tidal FeNO, clinical response to bronchodilator, and the asthma predictive index..$^{73}$

A new index to help identify future risk of wheezing in infants with a first episode of wheezing has been proposed 
by Zhang et al. ${ }^{74}$ Infants aged 2 months through to 20 months were followed after their first episode of wheezing for 2 years. Their personal and family history of atopic diseases was recorded. Wheezing severity was evaluated using the Preschool Respiratory Assessment Measure. Sputum samples were collected from patients, stained with hematoxylin and eosin, and studied by optical microscopy. The number of shed exfoliated airway epithelial cells was counted. The predictive value of exfoliated airway epithelial cells counted, family or personal history of atopic disease, and severity of wheezing for subsequent development of wheezing were analyzed. A sensitivity of $95.1 \%$, a specificity of $74.2 \%$, a positive predictive value of $58.6 \%$, and a negative predictive value of $93.6 \%$ for prediction of wheezing was demonstrated for an index combining a wheezing severity score of 9,495 sputum exfoliated airway epithelial cells and a family or personal history of atopic disease. ${ }^{74}$

In a retrospective study designed to establish predictive factors for persistence of asthma during adolescence in a population of recurrent wheezing infants, 227 infants younger than 36 months of age who had a history of at least three doctor-diagnosed wheezing episodes were evaluated. At 13 years, active asthma was assessed by questionnaire. The results indicated that risk factors for asthma persisting into adolescence were: allergic sensitization to multiple airborne allergens, initial atopic dermatitis, severe recurrent wheezing, and hypereosinophilia $>470 / \mathrm{mm}^{3}$. The conclusion of the study was that atopy is a major risk factor for persistence of asthma. ${ }^{75}$

\section{Prevention}

Investigators have conducted interventional and observational studies to explore the potential of reducing the odds of development of asthma among children at higher risk. Interventions have included breastfeeding, probiotics, and reduction of exposure. ${ }^{64,76,77}$ None of these interventions were effective in preventing the development of asthma among children with wheeze or at risk for wheeze.

\section{Discussion}

Childhood wheeze is common and is the cause of a large burden for the affected child, their family, and society at large. Clinicians are in need of simple-to-use, well-validated tools to determine which children who wheeze will progress to develop asthma. Over the last few decades, progress has been made in determining risk factors for the development of wheeze and asthma; however, efforts are hampered by the multiple phenotypes of asthma and the complexity of the disease.
Investigators have attempted to identify clusters or phenotypes of childhood wheeze. Unfortunately, there is no simple consensus classification system for children with wheeze that would enhance research efforts. The most widely used classification system for childhood asthma is that proposed by the National Institutes of Health asthma management guidelines, but this system applies to children with asthma not infant wheeze. While many investigators endorse the classification originating from the Tucson Children's Respiratory Study, it is not universally established as the system for classification of wheeze in children, and cannot be used until the wheeze pattern has been established at around the age of 6 years. A system for early classification of early childhood wheezers might help inform research of treatment options for different phenotypes.

There are no genetic tests to identify which children who wheeze will develop asthma, and many of the genetic studies have not been replicated. Moreover, genetics only explain a small portion of the risk for development of asthma.

Many environmental factors contribute to the development of asthma. No single exposure has been associated with an increase in prevalence of asthma, so it is likely that the changes in asthma prevalence are likely related to a combination of environmental exposures and genetic susceptibility (Figure 2).

Clinicians are also hampered by a paucity of objective testing options that can be used to predict which children with wheeze will develop asthma. Current predictive indices often can only be applied after many wheezing episodes, were developed solely based on expert opinion, or are of limited clinical applicability. Other objective tools involve maneuvers that are difficult for young children to perform or are of limited predictive value beyond specific individual asthma phenotypes.

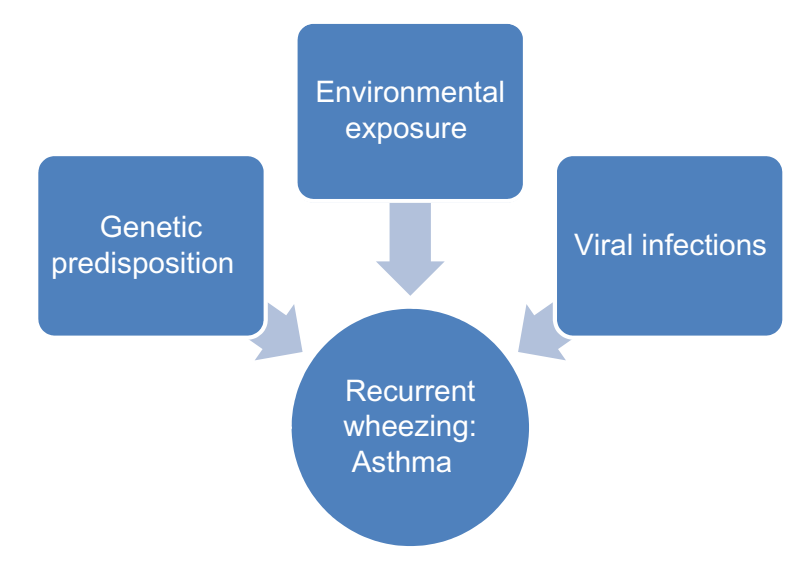

Figure 2 Complex etiology of recurrent wheezing and asthma. 
Another challenge in the field is that early intervention studies among children who wheeze have demonstrated limited influence on the course of the disease or development of asthma. If efforts to intervene early in pathogenesis are of limited value, families may have less motivation to seek early treatment beyond acute episodes.

\section{Conclusion}

Childhood wheeze is common and a substantial burden. Tools to identify children who will develop asthma are limited, and early intervention options have not proven efficacious. Additional research is needed to clarify childhood wheeze phenotypes, to develop tools that can determine which children will develop asthma, and to determine how and when to intervene. If these areas can be addressed, it would help reduce this large burden on children, families, and society.

\section{Disclosure}

The authors report no conflicts of interest in this work.

\section{References}

1. Ducharme FM, Tse SM, Chauhan B. Diagnosis, management, and prognosis of preschool wheeze. Lancet. 2014;383:1593-1604.

2. Mallol J, García-Marcos L, Solé D, Brand P; for the EISL Study Group. International prevalence of recurrent wheezing during the first year of life: variability, treatment patterns and use of health resources. Thorax. 2010;65:1004-1009.

3. Zar HJ, Ferkol TW. The global burden of respiratory disease-impact on child health. Pediatr Pulmonol. 2014;49:430-434.

4. Keet CA, McCormack MC, Pollack CE, Peng RD, McGowan E, Matsui EC. Neighborhood poverty, urban residence, race/ethnicity, and asthma: rethinking the inner-city asthma epidemic. J Allergy Clin Immunol. 2015;135:655-662.

5. Martinez FD. What have we learned from the Tucson Children's Respiratory Study? Paediatr Respir Rev. 2002;3:193-197.

6. Ruotsalainen M, Piippo-Savolainen E, Hyvärinen MK, Korppi M. Adulthood asthma after wheezing in infancy: a questionnaire study at 27 years of age. Allergy. 2010;65:503-509.

7. Chang TS, Lemanske J, Robert F, et al. Asthma and lower airway disease: childhood asthma clusters and response to therapy in clinical trials. J Allergy Clin Immunol. 2014;133:363-369. e3.

8. Fitzpatrick AM, Teague WG, Meyers DA, et al. Asthma and lower airway disease: heterogeneity of severe asthma in childhood: confirmation by cluster analysis of children in the National Institutes of Health/ National Heart, Lung, and Blood Institute Severe Asthma Research Program. J Allergy Clin Immunol. 2011;127:382-389. e13.

9. Klinnert MD, Nelson HS, Price MR, Adinoff AD, Leung DY, Mrazek DA. Onset and persistence of childhood asthma: predictors from infancy. Pediatrics. 2001;108:E69.

10. Taussig LM, Wright AL, Holberg CJ, Halonen M, Morgan WJ, Martinez FD. Tucson Children's Respiratory Study: 1980 to present. J Allergy Clin Immunol. 2003;111:661-675.

11. Savenije OE, Granell R, Caudri D, et al. Comparison of childhood wheezing phenotypes in 2 birth cohorts: ALSPAC and PIAMA. J Allergy Clin Immunol. 2011;127:1505-1512. e14.

12. Wenzel SE. Asthma: defining of the persistent adult phenotypes. Lancet. 2006;368:804-813.
13. Renkonen J, Joenväärä S, Parviainen V, Mattila P, Renkonen R. Network analysis of single nucleotide polymorphisms in asthma. J Asthma Allergy. 2010;3:177-186.

14. Yang KD, Ou C, Chang J, et al. Mechanisms of asthma and allergic inflammation: Infant frequent wheezing correlated to Clara cell protein 10 (CC10) polymorphism and concentration, but not allergy sensitization, in a perinatal cohort study. J Allergy Clin Immunol. 2007;120: 842-848.

15. Savenije OE, Mahachie John JM, Granell R, et al. Association of IL33-IL-1 receptor-like 1 (IL1RL1) pathway polymorphisms with wheezing phenotypes and asthma in childhood. JAllergy Clin Immunol. 2014;134:170-177.

16. Shaker OG, Sadik NA, El-Hamid N. Impact of single nucleotide polymorphism in tumor necrosis factor- $\alpha$ gene 308G/A in Egyptian asthmatic children and wheezing infants. Hum Immunol. 2013;74: 796-802.

17. García-Sánchez A, Isidoro-García M, García-Solaesa V, et al. Series: Genetics in Allergy III: Genome-wide association studies (GWAS) and their importance in asthma. Allergol Immunopathol (Madr). November 26, 2014. [Epub ahead of print.]

18. Moffatt MF, Kabesch M, Liang L, et al. Genetic variants regulating ORMDL3 expression contribute to the risk of childhood asthma. Nature. 2007;448:470-473.

19. Galanter J, Choudhry S, Eng C, et al. ORMDL3 gene is associated with asthma in three ethnically diverse populations. Am J Respir Crit Care Med. 2008;177:1194-1200.

20. Kang MJ, Yu HS, Seo JH, et al. GSDMB/ORMDL3 variants contribute to asthma susceptibility and eosinophil-mediated bronchial hyperresponsiveness. Hum Immunol. 2012;73:954-959.

21. Ferreira MA, Matheson MC, Duffy DL, et al. Identification of IL6R and chromosome 11q13.5 as risk loci for asthma. Lancet. 2011;378: 1006-1014.

22. Galanter JM, Gignoux CR, Torgerson DG, et al. Genome-wide association study and admixture mapping identify different asthmaassociated loci in Latinos: the Genes-environments and Admixture in Latino Americans study. J Allergy Clin Immunol. 2014;134: 295-305.

23. Wjst M, Sargurupremraj M, Arnold M. Genome-wide association studies in asthma: what they really told us about pathogenesis. Curr Opin Allergy Clin Immunol. 2013;13:112-118.

24. Gilmour MI, Jaakkola MS, London SJ, Nel AE, Rogers CA. How exposure to environmental tobacco smoke, outdoor air pollutants, and increased pollen burdens influences the incidence of asthma. Environ Health Perspect. 2006;114:627-633.

25. Dosanjh A. Childhood asthma and anthropogenic CO2 emissions J Asthma Allergy 2011;4:103-105.

26. Le Cann P, Bonvallot N, Glorennec P, Deguen S, Goeury C, Le Bot B. Indoor environment and children's health: recent developments in chemical, biological, physical and social aspects. Int J Hyg Environ Health. 2011;215:1-18.

27. Kanchongkittiphon W, Gaffin JM, Phipatanakul W. The indoor environment and inner-city childhood asthma. Asian Pac J Allergy Immunol. 2014;32:103-110.

28. Committee on the Medical Effects of Air Pollutants, 1998. The quantification of the effects of air pollution on health in the United Kingdom, London. Available from: http://ebookoninternet.com/1814854/ quantification-effects-air-pollution-health-united-kingdom-committeemedical-effects-air-pollutants.html. Accessed March 7, 2015.

29. World Health Organization, 2013. Review of evidence on health aspects of air pollution-REVIHAAP Project. Available from: http://www.euro. who.int/en/health-topics/environment-and-health/air-quality/publications/2013/review-of-evidence-on-health-aspects-of-air-pollutionrevihaap-project-final-technical-report. Accessed March 7, 2015.

30. Boehmer TK, Foster SL, Henry JR, Woghiren-Akinnifesi EL, Yip FY. Residential proximity to major highways - United States, 2010. Centers for Disease Control and Prevention (CDC). MMWR Surveill Summ. 2013;62 Suppl 3:46-50. 
31. Smith GE, Bawa Z, Macklin Y, et al. Using real-time syndromic surveillance systems to help explore the acute impact of the air pollution incident of March/April 2014 in England. Environ Res. 2015;136: 500-504.

32. Liu JC, Pereira G, Uhl SA, Bravo MA, Bell ML. A systematic review of the physical health impacts from non-occupational exposure to wild fire smoke. Environ Res. 2015;136:120-132.

33. Guarnieri M, Balmes JR. Outdoor air pollution and asthma. Lancet. 2014;383:1581-1592.

34. Gold DR, Burge HA, Carey V, Milton DK, Platts-Mills T, Weiss ST. Predictors of repeated wheeze in the first year of life: the relative role of cockroach, birth weight, acute lower respiratory illness, and maternal smoking. Am J Respir Crit Care Med. 1999;160:227-236.

35. Jaakkola JJ, Gissler M. Maternal smoking in pregnancy, fetal development, and childhood asthma. Am J Public Health. 2004;94: 134-140.

36. Magnus MC, Håberg SE, Karlstad Ø, Nafstad P, London SJ, Nystad W. Grandmother's smoking when pregnant with the mother and asthma in the grandchild: the Norwegian Mother and Child Cohort Study. Thorax. 2015;70:237-243.

37. Kerkhof M, Wijga AH, Brunekreef $\mathrm{B}$, et al; for the PIAMA study. Effects of pets on asthma development up to 8 years of age: the PIAMA study. Allergy. 2009;64:1202-1208.

38. Gent JF, Belanger K, Triche EW, Bracken MB, Beckett WS, Leaderer BP. Association of pediatric asthma severity with exposure to common household dust allergens. Environ Res. 2009;109:768-774.

39. Gent JF, Kezik JM, Hill ME, Tsai E, Li DW, Leaderer BP. Household mold and dust allergens: exposure, sensitization and childhood asthma morbidity. Environ Res. 2012;118:86-93.

40. Murray CS, Poletti G, Kebadze T, et al. Study of modifiable risk factors for asthma exacerbations: virus infection and allergen exposure increase the risk of asthma hospital admissions in children. Thorax. 2006;61:376-382.

41. Matsui EC, Wood RA, Rand C, Kanchanaraksa S, Swartz L, Eggleston PA. Mouse allergen exposure and mouse skin test sensitivity in suburban, middle-class children with asthma. J Allergy Clin Immunol. 2004;113:910-915.

42. Phipatanakul W, Celedon JC, Sredl DL, Weiss ST, Gold DR. Mouse exposure and wheeze in the first year of life. Ann Allergy Asthma Immunol. 2005;94:593-599.

43. Phipatanakul W, Celedón JC, Hoffman EB, Abdulkerim H, Ryan LM, Gold DR. Mouse allergen exposure, wheeze and atopy in the first seven years of life. Allergy. 2008;63:1512-1518.

44. Rosenstreich DL, Eggleston P, Kattan M, et al. The role of cockroach allergy and exposure to cockroach allergen in causing morbidity among inner-city children with asthma. N Engl J Med. 1997;336:1356-1363.

45. Rabito FA, Iqbal S, Holt E, Grimsley LF, Islam TM, Scott SK. Prevalence of indoor allergen exposures among New Orleans children with asthma. J Urban Health. 2007;84:782-792.

46. Wang J, Visness CM, Calatroni A, Gergen PJ, Mitchell HE, Sampson HA. Effect of environmental allergen sensitization on asthma morbidity in inner-city asthmatic children. Clin Exp Allergy. 2009;39: 1381-1389.

47. Celedon JC, Milton DK, Ramsey CD, et al. Exposure to dust mite allergen and endotoxin in early life and asthma and atopy in childhood. J Allergy Clin Immunol. 2007;120:144-149.

48. Antova T, Pattenden S, Brunekreef B, et al. Exposure to indoor mold and children's respiratory health in the PATY study. J Epidemiol Community Health. 2008;62:708-714.

49. Perzanowski MS, Miller RL, Thorne PS, et al. Endotoxin in inner city homes: associations with wheeze and eczema in early childhood. J Allergy Clin Immunol. 2006;117:1082-1089.

50. Matsui EC, Hansel NN, Aloe C, et al. Indoor pollutant exposures modify the effect of airborne endotoxin on asthma in urban children. Am J Respir Crit Care Med. 2013;188:1210-1215.

51. Weitzman M, Baten A, Rosenthal D, et al. Housing and child health. Curr Probl Pediatr Adolesc Health Care. 2013;43:187-224.
52. Cheng G, Smith AM, Levin L. Duration of day care attendance during infancy predicts asthma at the age of seven: the Cincinnati Childhood Allergy and Air Pollution Study. Clin Exp Allergy. 2014;44: 1274-1281.

53. Jackson DJ, Gangnon RE, Evans MD, et al. Wheezing rhinovirus illnesses in early life predict asthma development in high-risk children. Am J Respir Crit Care Med. 2008;178:667-672.

54. Miller EK, Williams JV, Gebretsadik T, et al. Asthma and lower airway disease: host and viral factors associated with severity of human rhinovirus-associated infant respiratory tract illness. J Allergy Clin Immunol. 2011;127:883-891.

55. Kusel MM, de Klerk NH, Kebadze T, et al. Early-life respiratory viral infections, atopic sensitization, and risk of subsequent development of persistent asthma. J Allergy Clin Immunol. 2007;119:1105-1110.

56. Torres D, Dieudonné A, Ryffel B, et al. Double-stranded RNA exacerbates pulmonary allergic reaction through TLR3: implication of airway epithelium and dendritic cells. J Immunol. 2010;185:451-459.

57. Kato A, Favoreto S Jr, Avila PC, Schleimer RP. TLR3- and Th2 cytokine-dependent production of thymic stromal lymphopoietin in human airway epithelial cells. J Immunol. 2007;179:1080-1087.

58. Zaitsu M. The development of asthma in wheezing infants with Chlamydia pneumoniae infection. J Asthma. 2007;44:565-568.

59. Kramer MS, Matush L, Vanilovich I, et al; for the PROBIT Study Group. Effect of prolonged and exclusive breast feeding on risk of allergy and asthma: cluster randomized trial. BMJ. 2007;335:815.

60. Bandoli G, von Ehrenstein OS, Flores ME, Ritz B. Breastfeeding and asthmatic symptoms in the offspring of Latinas: the role of maternal nativity. J Immigr Minor Health. January 10, 2015. [Epub ahead of print.]

61. Kewalramani A, Bollinger ME. The impact of food allergy on asthma. J Asthma Allergy. 2010;3:65-74.

62. Cornell A, Shaker M, Woodmansee DP. Update on the pathogenesis and management of childhood asthma. Curr Opin Pediatr. 2008;20: 597-604.

63. Zutavern A, Brockow I, Schaaf B, et al; for the LISA Study Group. Timing of solid food introduction in relation to eczema, asthma, allergic rhinitis, and food and inhalant sensitization at the age of 6 years: results from the prospective birth cohort study LISA. Pediatrics. 2008;121:e44-e52.

64. Greer FR, Sicherer SH, Burks AW; for the American Academy of Pediatrics Committee on Nutrition. Effects of early nutritional interventions on the development of atopic disease in infants and children: the role of maternal dietary restriction, breastfeeding, timing of introduction of complementary foods, and hydrolyzed formulas. Pediatrics. 2008;121:183-191.

65. Martinez FD. Recognizing early asthma. Allergy. 1999;54:24-28.

66. Castro-Rodriguez J. Young infants with recurrent wheezing and positive asthma predictive index have higher levels of exhaled nitric oxide. J Asthma. 2013;50:162-165.

67. van de Kant KD, Jansen MA, Klaassen EM, et al. Elevated inflammatory markers at preschool age precede persistent wheezing at school age. Pediatr Allergy Immunol. 2012;23:259-264.

68. Cobos Barroso N, Pérez-Yarza EG, Sardón Prado O, Reverté Bover C, Gartner S, Korta Murua J. Exhaled nitric oxide in children: a noninvasive marker of airway inflammation. Arch Bronconeumol. 2008;44:41-51.

69. Taylor DR, Pijnenburg MW, Smith AD, De Jongste JC. Exhaled nitric oxide measurements: clinical application and interpretation. Thorax. 2006;61:817-827.

70. Pijnenburg MW, De Jongste JC. Exhaled nitric oxide in childhood asthma: a review. Clin Exp Allergy. 2008;38:246-259.

71. de Mir Messa I, Moreno Galdó A, Cobos Barroso N, Gartner S, Martín DV, Liñán Cortés S. Exhaled nitric oxide in children under 4 years of age with recurrent bronchitis. Arch Bronconeumol. 2009;45: 442-448.

72. Gabriele C, Nieuwhof EM, Van Der Wiel EC, et al. Exhaled nitric oxide differentiates airway diseases in the first two years of life. Pediatr Res. 2006;60:461-465. 
73. Elliott M, Heltshe SL, Stamey DC, Cochrane ES, Redding GJ, Debley JS. Exhaled nitric oxide predicts persistence of wheezing, exacerbations, and decline in lung function in wheezy infants and toddlers. Clin Exp Allergy. 2013;43:1351-1361.

74. Zhang Y, Zhou C, Liu J, Yang H, Zhao S. A new index to identify risk of multi-trigger wheezing in infants with first episode of wheezing. J Asthma. 2014;51:1043-1048.

75. Amat F, Vial A, Pereira B, Petit I, Labbe A, Just J. Predicting the LongTerm Course of Asthma in Wheezing Infants Is Still a Challenge. ISRN Allergy. 2011:1-5.
76. Gehring U, de Jongste JC, Kerkhof M, et al. The 8-year follow-up of the PIAMA intervention study assessing the effect of mite-impermeable mattress covers. Allergy. 2012;67:248-256.

77. Azad MB, Coneys JG, Kozyrskyj AL, et al. Probiotic supplementation during pregnancy or infancy for the prevention of asthma and wheeze: systematic review and meta-analysis. BMJ. 2013;347:f6471.

\section{Publish your work in this journal}

The Journal of Asthma and Allergy is an international, peer-reviewed open-access journal publishing original research, reports, editorials and commentaries on the following topics: Asthma; Pulmonary physiology; Asthma related clinical health; Clinical immunology and the immunological basis of disease; Pharmacological interventions and

\section{Dovepress}

new therapies. Issues of patient safety and quality of care will also be considered. The manuscript management system is completely online and includes a very quick and fair peer-review system, which is all easy to use. Visit http://www.dovepress.com/testimonials.php to read real quotes from published authors.

Submit your manuscript here: http://www.dovepress.com/journal-of-asthma-and-allergy-journal 